[Article]

\title{
钙钛矿铁电纳米片诱导的 P(VDF-TrFE)取向生长
}

\author{
刘 金 ${ }^{1, \dagger}$ 麦江泉 ${ }^{2, \dagger}$ 李 诗 ${ }^{1}$ 任召辉 ${ }^{1,}{ }^{*}$ 李 铭 $^{1}$ 武梦娇 ${ }^{1}$ \\ 吴勇军 ${ }^{1}$ 路新慧 ${ }^{2,}$ 李 翔 $^{1}$ 田 鹤 $^{3}$ 王宗荣 ${ }^{1}$ 韩高荣 ${ }^{1, *}$
}

( ${ }^{1}$ 浙江大学材料科学与工程学院, 硅材料国家重点实验室, 唐仲英传感材料及应用研究中心, 杭州 310027 ;

2 香港中文大学物理系, 香港 新界 $999077{ }^{3}$ 浙江大学电子显微镜中心, 硅材料国家重点实验室,

材料科学与工程学院, 杭州 310027)

\begin{abstract}
摘要: 半结晶的铁电聚合物在柔性电子器件中极具应用前景, 控制晶相生长对其性能优化至关重要。本 文通过引入少量 $(0.2 \%)$ 单晶单畴的 $\mathrm{PbTiO}_{3}$ 纳米片对 $\mathrm{P}(\mathrm{VDF}-\mathrm{TrFE}$ ) (简称PVTF) 铁电薄膜的生长进行有效 调节, 获得了高度取向的铁电薄膜且铁电性能得到了大幅提高。 $\mathrm{PbTiO}_{3}$ 纳米片铁电极化对PVTF极性分 子的诱导作用可能是薄膜取向生长与性能提高的原因。
\end{abstract}

关键词: $\mathrm{P}(\mathrm{VDF}-\mathrm{TrFE}) ; \mathrm{PbTiO}_{3}$; 纳米片; 取向生长; 铁电性

中图分类号: 0641

\section{Perovskite Ferroelectric Nanoplates Induced a Highly Oriented Growth of P(VDF-TrFE) Films}

\author{
LIU Jin ${ }^{1, \dagger} \quad$ MAI Jiang-Quan ${ }^{2, \dagger}$ \\ LI Shi ${ }^{1}$ \\ REN Zhao-Hui ${ }^{1, *}$ \\ LI Ming $^{1}$ \\ WU Meng-Jiao ${ }^{1}$ WU Yong-Jun ${ }^{1}$ \\ LU Xin-Hui ${ }^{2, *}$ \\ LI Xiang ${ }^{1}$ \\ TIAN He \\ WANG Zong-Rong \\ HAN Gao-Rong ${ }^{1, *}$
}

( ${ }^{1}$ State Key Laboratory of Silicon Materials, School of Materials Science and Engineering, Cyrus Tang Center for Sensor Materials and Application, Zhejiang University, Hangzhou 310027, P. R. China; ${ }^{2}$ Department of Physics, Chinese University of Hong Kong, New Territories, Hong Kong 999077, P. R. China; $\quad{ }^{3}$ State Key Laboratory of Silicon Material, School of Material Science \& Engineering, Center of Electron Microscope, Zhejiang University, Hangzhou 310027, P. R. China)

\begin{abstract}
Ferroelectric polymers are particularly attractive for applications in flexible electronic devices, and controlling its crystalline phase growth is crucial for obtaining optimized ferroelectric properties. Herein we report that a very low introduction $(0.2 \%(w))$ of single-domain ferroelectric $\mathrm{PbTiO}_{3}$ nanoplates can effectively mediate the nucleation and subsequent growth of a crystalline phase within P(VDF-TrFE) (denoted by PVTF), forming highly oriented films and significantly improving the ferroelectric properties due to an alignment of the polarization directions of the polymer and the nanoplates.
\end{abstract}

Key Words: $\mathrm{P}(\mathrm{VDF}-\mathrm{TrFE}) ; \quad \mathrm{PbTiO}_{3} ; \quad$ Nanoplate; Orientation growth; Ferroelectricity

\footnotetext{
Received: February 15, 2017; Revised: February 27, 2017; Published online: March 6, 2017.

"Corresponding authors. REN Zhao-Hui, Email: renzh@zju.edu.cn. LU Xin-Hui, Email: xhlu@phy.cuhk.edu.hk. HAN Gao-Rong, Email: hgr@zju.edu.cn. $\dagger$ These authors contributed equally to this work.

The project was supported by the National Natural Science Foundation of China (51232006, 51472218), the National Key Basic Research Special Foundation, China (973) (2015CB654901), Fundamental Research Funds for the Central Universities, China (2016FZA4005) and RGC of Hong Kong GRF (14303314) and CUHK Direct Grant, China (4053128).

国家自然科学基金(51232006，51472218), 国家重点基础研究发展项目(973)(2015CB654901), 中央高校基本科研业务费专项资金(2016FZA4005), 香 港研究资助局科研基金(14303314)，香港中文大学基金(4053128)资助项目
}

(C) Editorial office of Acta Physico-Chimica Sinica 


\section{Introduction}

As a classical ferroelectric polymer, PVDF and its copolymer PVTF have been extensively explored in terms of dielectric, piezoelectric and ferroelectric properties, affording wide potential applications in flexible electronics from energy harvesting, data storage, sensors and actuators ${ }^{1-5}$. The electric properties and device performance of PVTF films highly depend on the crystallographic orientation of $\beta$ phase (ferroelectric phase) ${ }^{6-8}$. A prominent example is that a PVTF film with pressure-induced oriented crystalline exhibits an improved remnant polarization, 1.6 times higher than that of disordered counterpart ${ }^{9}$. To obtain such a preferential orientation, different physical templates, including anodic aluminium oxide $(\mathrm{AAO})^{10}$, organosilicate (OS) lamellae ${ }^{11}$, SAM-modified Au substrates ${ }^{12}$, graphene layer ${ }^{13}$, etc. have been employed. Among them, a confinement effect originating from microstructure of the templates was demonstrated to effectively induce the polarization direction along the long axis of one dimensional PVTF nanotubes ${ }^{14}$. However, the preparation and removal of the templates have been found to be very complex and tedious, significantly limiting large scale material and device fabrication. In addition, the epitaxy growth method normally employed for inorganic crystalline films cannot be simply applied for organic ferroelectric polymers due to the semi-crystalline character. Hence, it remains a great challenge to develop a facile strategy to fabricate highly oriented PVTF film.

In this work, for the first time, we demonstrated a facile and effective approach to mediate the growth and thus the orientation of PVTF films by a strong electrostatic interaction between PVTF and perovskite ferroelectric nanoplates. A very low introduction $(0.2 \%(w))$ of single-crystal and single-domain $\mathrm{PbTiO}_{3}$ (denoted by PTO) nanoplates can effectively mediate the nucleation and growth process of crystalline phase within PVTF, giving rise to highly (110)/(200) oriented films. We attributed this oriented crystallization behaviour to an alignment of polarization directions of the polymer and the nanoplates. As a result, the ferroelectric polarization of the films have been significantly improved by $53 \%$.

Negative or positive polar surface of ferroelectric perovskite oxides has been explored to accelerate the crystal growth of inorganic crystals ${ }^{15}$ and to influence the selective deposition of $\mathrm{Ag}$ particles on ferroelectric substrates by a photochemical $\operatorname{method}^{16}$. Moreover, the ordering of polar water molecules is observed within the ice films growing on the surface of $\mathrm{PVTF}^{17}$.

The electrostatic interaction between polar surface of ferroelectrics and different inorganic objects leads to fasnating phenomena. However, an effect of ferroelectric polarization on the crystal growth of semi-crystalline polymer films has not been achieved yet, and the difficulty arises from the semi-crystalline nature of polymer films with complex molecular configuration. To realize this, a strong electrostatic interaction is highly required. As a prototypical ferroelectric oxide, PTO is an ideal material to investigate the effect of electrostatic interaction on the growth of PVTF because of its simple perovskite structure and large spontaneous polarization $\left(P_{\mathrm{s}}\right)^{18}$.

Fig.1(a, b) present the schematic view of the crystal structures for tetragonal PTO (JCPDS 70-0746) and the orthorhombic $\beta$-phase PVTF (JCPDS 42-1649), where the $P_{\mathrm{s}}$ is along the $c$ axis and $b$ axis, respectively. The relative displacement of $\mathrm{Ti}$ ions from oxygen plane of octahedron in Fig.1(a) gives rise to a $P_{\mathrm{s}}$ of PTO. In our previous work, single-crystal and single-domain PTO nanoplates were synthesized hydrothermally via a self-templated growth ${ }^{19}$. A cross-section STEM image of an individual PTO nanoplate is shown in Fig.1(c), and the nanoplate adopts faceted planes with a smooth surface. Fig.1(d) depicts the corresponding atomic-level HAADF-STEM of the nanoplate (red area in Fig.1(c)), where the displacement of titanium atoms deviation from the body-center downwards can be observed, opposite to the ferroelectric polarization direction ${ }^{20}$. Thus, the polarization direction (pointing by an orange arrow) of the nanoplate is perpendicular to the surface in Fig.1(d). In particular, the Curie temperature of the nanoplates was determined to be $487{ }^{\circ} \mathrm{C}$ (Fig.S2), very close to $490{ }^{\circ} \mathrm{C}$ of bulk PTO, implying a large Ps of the nanoplates with an order of $60 \sim 70 \mu \mathrm{C} \cdot \mathrm{cm}^{-2}{ }^{21}$. This value is much larger than those of polar organic molecules and ferroelectric polymer ${ }^{17,22,23}$. When unscreened, an electrostatic field derived from the polar surface of PTO nanoplates could be high as $10^{8} \mathrm{~V} \cdot \mathrm{cm}^{-1} 23$.

\section{Experiment section \\ 2.1 Material preparation}

Single-crystal and single-domain ferroelectric PTO nanoplates were synthesized by hydrothermal synthesis
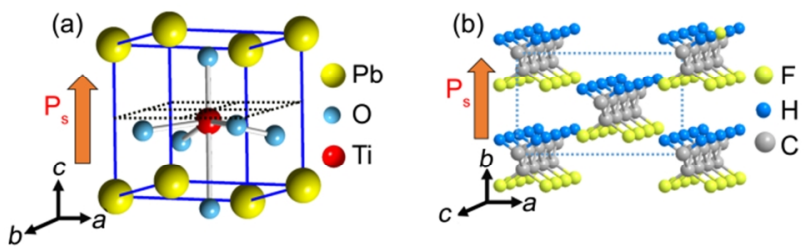

(c)

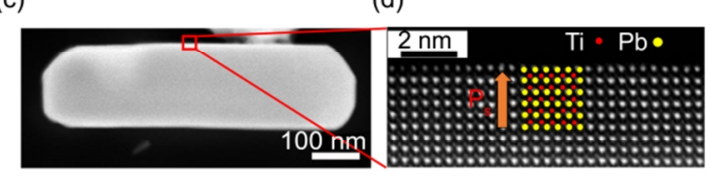

Fig.1 Schematic view of the crystal structures for (a) tetragonal $\mathrm{PbTiO}_{3}$ and (b) orthorhombic $\beta$-phase PVTF, (c) Cross-section TEM image of individual PTO nanoplate and (d) corresponding atomic level HAADF-STEM (SEM image and XRD pattern see Fig.S1(a, b) 
method ${ }^{19} \cdot \mathrm{TiO}_{2}$ nanosheets were prepared according to the method reported in the reference ${ }^{24} .25 \mathrm{~mL}$ of $\mathrm{Ti}(\mathrm{OBu})_{4}$ and 4 $\mathrm{mL}$ of hydrofluoric acid solution were mixed in a dried Teflon autoclave with a capacity of $50 \mathrm{~mL}$, and then kept at $200{ }^{\circ} \mathrm{C}$ for 24 h. After being cooled to room temperature, the white powder was washed with ethanol and distilled water for several times and then dried at $80{ }^{\circ} \mathrm{C}$ for $6 \mathrm{~h}$.

PVTF (the mole ratio of VDF to TrFE is 70/30) powder was dissolved in tetrahydrofuran (THF) and then a certain PTO (or $\mathrm{TiO}_{2}$ ) powder was introduced into the solution. The mixed hybrid was then processed with stirring for $15 \mathrm{~min}$ and then sonicating $30 \mathrm{~min}$ in order to disperse the nanoplates completely. Here we designed the weight concentration of PTO (or $\mathrm{TiO}_{2}$ ) nanoplates as $0.2 \%, 0.5 \%$, and $1.0 \%$ within PVTF. The pure PVTF and PVTF films with $0.2 \%$ PTO $\left(\mathrm{TiO}_{2}\right)$ nanoplates were prepared by a spin coating technique on the ITO glass substrates under a speed of $1500 \mathrm{rpm}$ for $30 \mathrm{~s}$. In particular, the substrates were cleaned by sonicating in the deionized water, acetone and ethanol for $15 \mathrm{~min}$, respectively. Finally, the as-prepared films were heated under vacuum condition for different time and then cooled down to room temperature. In order to measure the electric properties, Ag film was sputtered onto the surface of films as top electrode while ITO was used as the bottom electrode.

\subsection{Characterization}

The XRD patterns were collected on a Thermo ARLXTRA powder diffractometer with $\mathrm{Cu} K_{\alpha}$ radiation $\left(\lambda=1.54056 \mathrm{~nm}^{-}\right.$ $\left.{ }^{1}\right)$. SEM images were obtained from a Hitachi field emission SEM MODEL S-4800 at $5 \mathrm{kV}$. TEM specimens were examined by using an FEI Titan G2 80-200 Chemi 280 STEM with an accelerating voltage of $200 \mathrm{kV}$. Non-contact mode AFM (XE-100E, Park, Korea) was conducted to analyze topographic of films and Fourier transform infrared (FTIR) (Tensor 27, Bruker, Germany) was used to identify the molecule structures of films. The thickness of pure PVTF and PVTF (0.2\%) films were detected by a step profiler (DEKTAK-XT, Bruker, America). The enthalpy values for the two samples were derived from TG curves recorded on a PE DSC 7. The Curie temperature of PTO nanoplates was detected by a technique of TG-DTA, combining TG ignition measurement and DTA analysis, equipped with the analyzer TGA7 (Perkin Elmer, San Jose, CA, USA) and DTA7 (Perkin Elmer, San Jose, CA, USA), respectively. The GIWAXS measurements were conducted at 23A SWAXS beamline at the National Synchrotron Radiation Research Center, Hsinchu, Taiwan, using a $10 \mathrm{KeV}$ primary beam, $2.0^{\circ}$ incident angle and C9728DK area detector. Dielectric properties of the samples were measured by Agilent 4292A precision impedance analyzer (HP4294ALRC) between $1 \mathrm{KHz}$ and $1 \mathrm{MHz}$. Ferroelectric properties of the samples were measured at 100 $\mathrm{Hz}$ using a RT66A ferroelectric tester (Radiant Technologies Inc., Albuquerque, NM, USA).

\section{Results and Discucssion}

For such nanoplates, the exposed (001) is positive or negative polar surface, and the direction of $P_{\mathrm{s}}$ is uniformed within the nanoplate along c axis. Different concentration of PTO nanoplates was introduced into PVTF films with similar thicknesses about $800 \mathrm{~nm}$, prepared by spin-coating on ITO substrates (see Experiment section). According to the XRD patterns in Fig.S3(a), the peak intensity of (001) is the highest among those of PTO in the film, implying that most PTO nanoplates are lying in PVTF films. When PTO nanoplates were introduced, the intensity of $(110) /(200)$ diffraction peaks in PVTF films with $0.2 \%, 0.5 \%$ and $1.0 \%$ PTO nanoplates is higher than that of PVTF ( $0 \%)$ films (Fig.S3(a)), implying that an orientation growth could occur. In particular, PVTF films with $0.2 \%(w)$ PTO nanoplates (denoted by PVTF $(0.2 \%)$ films) present the highest relative intensity ratio of $(110) /(200)$ $\left(\sim 19.8^{\circ}\right)$. Furthermore, grazing incidence wide-angle X-ray scattering (GIWAXS) was used to investigate molecular orientation. Fig.2(a, b) show GIWAXS patterns of pure PVTF and PVTF $(0.2 \%)$ films, respectively. It can be clearly observed that at $q \approx 14 \mathrm{~nm}^{-1}$, PVTF $(0.2 \%)$ film has two distinct reflections at meridian and $60^{\circ}$ away from the meridian indicating a highly preferential orientation, while the pure PVTF film shows a ring-like pattern representing a randomly distributed orientation. The two reflections are corresponding to (200) and (110). These reflections arise from either (110) or (200) of PVTF crystals, based on the fact that the PVTF crystal phase has a pseudo hexagonal orthorhombic lattice which is characterized by a $\sqrt{2 / 3}$ ratio of its a and $b$ axes and in turn leads to nearly equal (200) and (110) spacings ${ }^{25}$. Two possible orientations of the PVTF films are illustrated in Fig.3(a, b). The case one is that (200) of PVTF parallel to (001) of PTO, where the Ps direction of PVTF is perpendicular to that of PTO, as shown in Fig.3(a). This configuration gives rise to the reflection of (200) on the meridian. In the case two, (110) of PVTF is paralleled to (001) of PTO, where the reflection on the meridian is thus indexed as (110) in Fig.3(b). Although the two reflections are hard to be distinguished due to the same lattice constant, we presume that the case in Fig.3(b) is more possible since the polarization direction of PVFT and PTO should align together to induce this preferential orientation. And the aligned dipoles of PVTF would further affect the other dipoles around. In addition, $0.5 \%$, and $1.0 \%$ samples also show the similar two reflections but their intensity is relatively weak (Fig.S4). This result indicates an orientation growth also occurred in these films as well, consistent with the XRD results of Fig.S3(a). In the emerged work, it has been discussed that an oriented growth of PVTF films could be thickness-dependent due to molecular confinement effect. However, such effect is limited to ultrathin films $(<100 \mathrm{~nm})$, resulting in a decreased ferroelectric property ${ }^{26,27}$. Therefore, the molecular confinement effect cannot give rise to the highly preferential orientation of PVTF films in our work. 

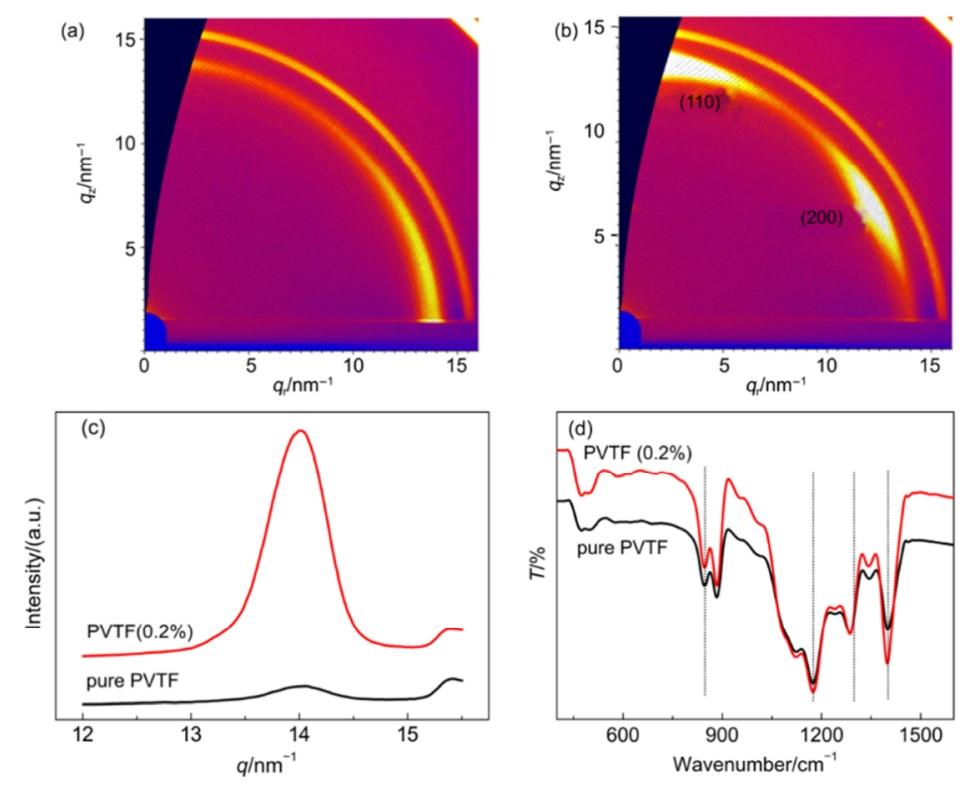

Fig.2 (a, b) GIWAXS patterns, (c) corresponding intensity profiles along $q_{z}$ axis and (d) FTIR spectrum of pure PVTF film and PVTF (0.2\%) film

We also argued that an improved crystallization cannot be the origin of such phenomenon because it can only lead to a general increase of all peaks instead of a single peak. Furthermore, the crystallinity degree $X_{\mathrm{c}}$ for the two samples has been determined by DSC curves (Fig.S5) to be 59.6\% and $61.5 \%$, respectively. Despite of similar crystallinity, the morphology by AFM imaging is obviously different, from particle shape in pure PVTF film to long-rod shape in PVTF $(0.2 \%)$ film, as shown in Fig.S6(a, b). On the basis of the corresponding 3D view image, an average diameter of the particles in pure PVTF (Fig.S6(c)) is statically about $0.38 \mu \mathrm{m}$, and the rods in PVTF (0.2\%) film in Fig.S6(d) was determined to have an average diameter of $0.45 \mu \mathrm{m}$ and length of $1.54 \mu \mathrm{m}$. The anisotropic morphological shape is most likely to result from the highly oriented growth of the film induced by the introduction of PTO nanoplates.

On the basis of the model in Fig.3(b), the polarization axis ( $b$ axis) of PVTF film tend to be aligned by that of PTO nanoplate and thus form an angle of $60^{\circ}$ with the normal direction of the nanoplates. Such configuration would lead to a strong electrostatic interaction between molecular chain of PVTF and PTO. The interaction can be manifested by the band of 1400 $\mathrm{cm}^{-1}$ of PVTF in FTIR spectrum, corresponding to the $\mathrm{\omega CH}_{2}$ coupled with $v_{\mathrm{as}} \mathrm{C}-\mathrm{C}^{28}$. From the FTIR spectra (Fig.2(d)), it can be observed that the peak intensity of the band of $1400 \mathrm{~cm}^{-1}$ in PVTF $(0.2 \%)$ film becomes much higher than that of pure PVTF, supporting our model of Fig.3(b). The other bands at $846 \mathrm{~cm}^{-1}, 1174 \mathrm{~cm}^{-1}$ and $1286 \mathrm{~cm}^{-1}$ in Fig.2(d) are indexed as the $\mathrm{CF}_{2}$ symmetric stretching, the $\mathrm{CF}_{2}$ asymmetric stretching and the long trans sequence ${ }^{29-31}$.

The growth process of PVTF film was further investigated by using PVTF (0.2\%) films after a heat treatment of $180{ }^{\circ} \mathrm{C}$
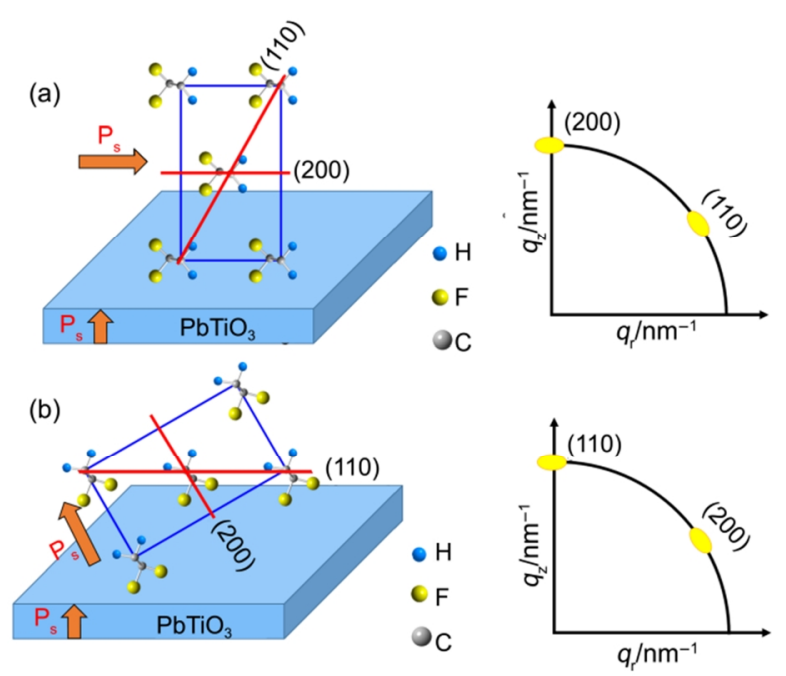

Fig.3 A schematic diagram of two possible cases that the molecular preferentially oriented

for different time. The intensified GIWAXS reflection in Fig.4(a) suggests that the film became crystalline after $0.5 \mathrm{~h}$ heat treatment, and the crystallization gradually improved up to $1 \mathrm{~h}$ in Fig.4(b). A longer time of $1.5 \mathrm{~h}$ could also induce the $(110) /(200)$ orientation growth of the film, confirmed by the two intensified reflections in Fig.4(c). The orientation of the film remained when the heat treatment was prolonged to $2.0 \mathrm{~h}$ in Fig.4(d). Corresponding topographic morphology of the samples were characterized by AFM in Fig.4 $(\mathrm{e}-\mathrm{h})$. PVTF $(0.2 \%)$ film was initially crystallized into particle, as shown in Fig.4(e, f), and then particle crystals gradually grew to a rod-like shape (Fig.4(g, h)). The above results provide the solid evidence to support that the films experience a nucleation-growth process, accompanied with the orientation and the distinct morphology change. One should note that a high temperature of $180{ }^{\circ} \mathrm{C}$ used for preparation is above 

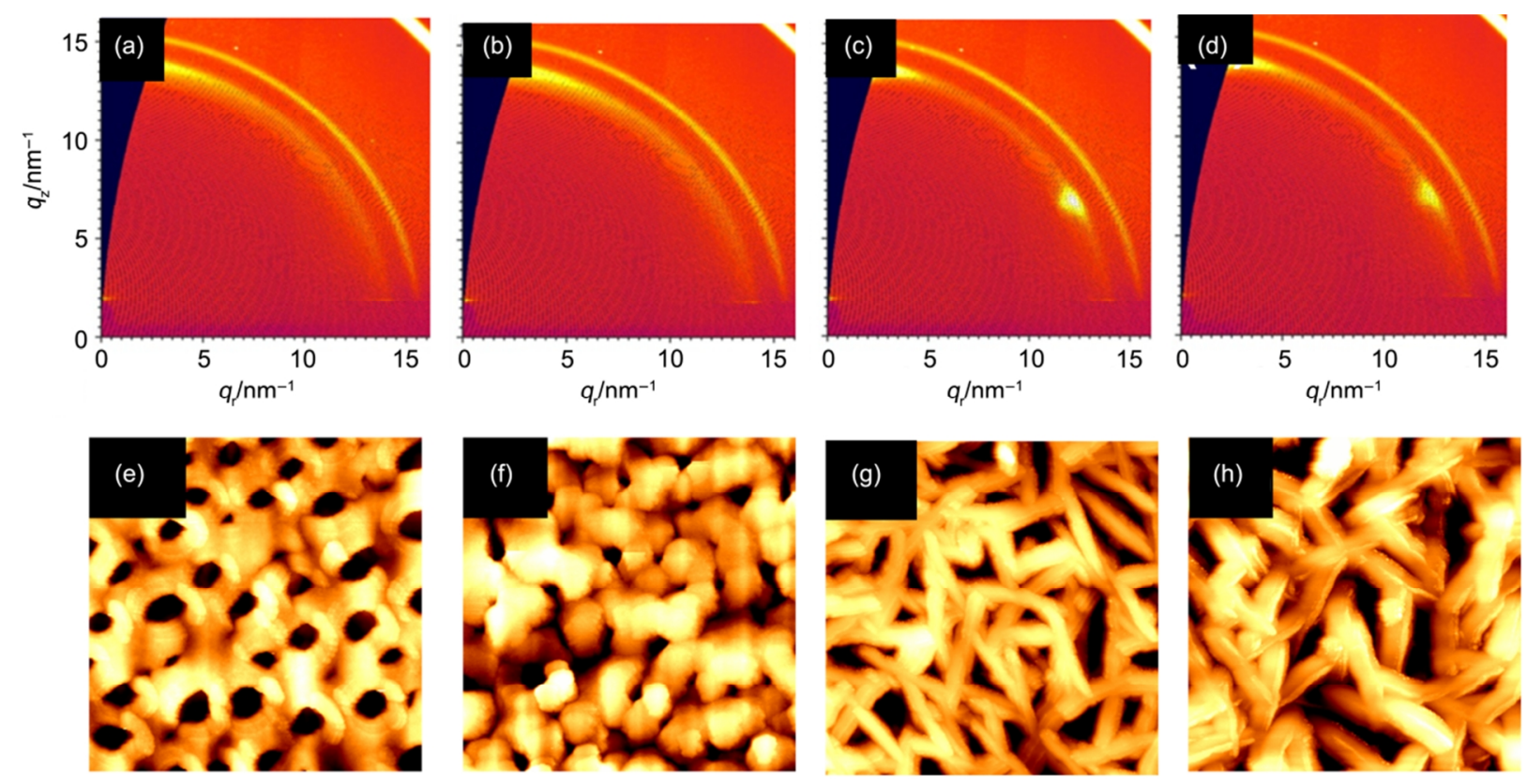

Fig.4 GIWAXS patterns of PVTF (0.2\%) films heat treated at $180^{\circ} \mathrm{C}$ for (a) $0.5 \mathrm{~h}$, (b) $1.0 \mathrm{~h}$, (c) $1.5 \mathrm{~h}$, (d) $2.0 \mathrm{~h}$ and (e-h) corresponding AFM

topographic images $(5 \mu \mathrm{m} \times 5 \mu \mathrm{m})$

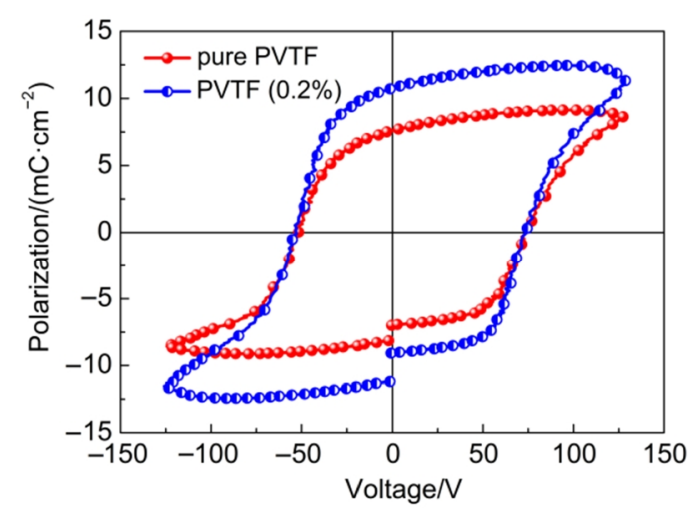

Fig.5 Ferroelectric hysteresis loops of pure PVTF and PVTF (0.2\%) films

melting temperature $\left(T_{\mathrm{m}}\right)\left(\sim 150{ }^{\circ} \mathrm{C}\right)$ of PVTF (Fig.S5), at which the molecular chains of PVTF can freely reorganize. This could be particularly important for ferroelectric polarization inducing the array of the

chains and subsequent preferential orientation of the films, as shown in Fig.1(d). When the thickness is below $100 \mathrm{~nm}$, the annealing temperature could play an important role in modifying confinement effect and thus the orientation of $\mathrm{P}(\mathrm{VDF}-\mathrm{TrFE})$ films $^{26,27,32}$. However, no such orientation growth has been observed when our samples, such as PVTF (0.2\%) films, were prepared at below $T_{\mathrm{m}}\left(120^{\circ} \mathrm{C}\right)$ (see Fig.S7) Furthermore, non-ferroelectric $\mathrm{TiO}_{2}$ nanoplates (SEM image see Fig.S8) were introduced to investigate their influence on the growth of PVTF films. And such PVTF films did not show such orientation like Fig.2(b) by analysing GIWAXS patterns (Fig.S9). It is thus reasonable to conclude that the temperature above $T_{\mathrm{m}}$ and ferroelectric polarization are crucial for the oriented growth of PVTF films. Accompanying with the oriented growth, the peak intensity at $1400 \mathrm{~cm}^{-1}$ was significantly enhanced in FTIR spectra of PVTF $(0.2 \%)$ films (Fig.S10) as the heat time was prolonged from $0.5 \mathrm{~h}$ to $2 \mathrm{~h}$ at $180^{\circ} \mathrm{C}$. These results strongly support our model in Fig.3(b). In particular, a significant improvement in ferroelectric property has been achieved in such PVTF $(0.2 \%)$ films.

On the basis of ferroelectric hysteresis loops in Fig.5, the remnant polarization (Pr) in Fig.5 increased from $7.0 \mu \mathrm{C} \cdot \mathrm{cm}^{-2}$ to $10.7 \mu \mathrm{C} \cdot \mathrm{cm}^{-2}$. We believe that the improved properties should be attributed to the oriented growth and dipole arrangement in the films. One may argue that the introduction of PTO nanoplates might also contribute to the results in Fig.5. To investigate this aspect, the ferroelectric property of PVTF films with different concentrations of PTO that nanoplates were measured. The results indicate the properties were not improved upon the increased concentrations of PTO nanoplates (Fig.S11 and Fig.S12). When the concentration of PTO nanoplates is $0.2 \%$, the properties of the films could be optimized.

\section{Summary}

In summary, a highly oriented PVTF film was obtained by the introduction of a very small amount of single-crystal and single-domain PTO nanoplates. The corresponding structural analysis revealed that with the optimum concentration of $0.2 \%$ $(w)$, the electrostatic interaction between PTO polar surface and dipoles of PVTF molecular chains can effectively mediate the nucleation and growth of PVTF, giving rise to a strong orientation. By this means, the ferroelectric polarization of the samples have been improved by $53 \%$, which is of great significance for device applications. The findings suggest that the introduction of ferroelectric nanoplates may be a facile approach to tailor the crystalline growth of polar organic materials and their fundamental physical properties. 
Supporting Information: available free of charge via the internet at http://www.whxb.pku.edu.cn.

\section{References}

(1) Soin, N.; Boyer, D.; Prashanthi, K.; Sharma, S.; Narasimulu, A. A; Luo, J.; Shah, T. H.; Siores, E.; Thundat, T. Chem. Commun. 2015, 51, 8257. doi: $10.1039 / \mathrm{c} 5 \mathrm{cc} 01688 \mathrm{f}$

(2) Hu, Z.; Tian, M.; Nysten, B.; Jonas, A. M. Nat. Mater. 2009, 8 , 62. doi: 10.1038/NMAT2339

(3) Chen, X. Z.; Li, Q.; Chen, X.; Guo, X.; Ge, H. X.; Liu, Y.; Shen, Q. D. Adv. Funct. Mater. 2013, 23, 3124. doi: 10.1002/adfm.201203042

(4) Wang, X.; Wang, P.; Wang, J.; Hu, W.; Zhou, X.; Guo, N.; Huang, H.; Sun, S.; Shen, H.; Lin, T.; Tang, M. Adv. Mater. 2015, 27, 6575. doi: 10.1002/adma.201503340

(5) Lee, J. S.; Shin, K. Y.; Kim, C.; Jang, J. Chem. Commun. 2013, 49, 11047. doi: 10.1039/c3cc46807k

(6) Ohigashi, H.; Omote, K.; Gomyo, M. C. Appl. Phys. Lett. 1995, 66, 3281. doi: 10.1063/1.113730

(7) García-Gutiérrez, M. C.; Linares, A.; Hernández, J. J.; Rueda, D. R.; Ezquerra, T. A.; Poza, P.; Davies, R. J. Nano Lett. 2010, 10, 1472. doi: $10.1021 / \mathrm{n} 1100429 \mathrm{u}$

(8) Wu, Y.; Li, X.; Jonas, A. M.; Hu, Z. Phys. Rev. Lett. 2015, 115, 267601. doi: 10.1103/PhysRevLett.115.267601

(9) Shin, Y. J.; Kim, R. H.; Jung, H. J.; Kang, S. J.; Park, Y. J.; Bae, I. Park, C. ACS Appl. Mater. Interfaces 2011, 3, 4736. doi: $10.1021 / \mathrm{am} 201202 \mathrm{w}$

(10) Cauda, V.; Torre, B.; Falqui, A.; Canavese, G.; Stassi, S.; Bein, T.; Pizzi, M. Chem. Mater. 2012, 24, 4215. doi: $10.1021 / \mathrm{cm} 302594 \mathrm{~s}$

(11) Kang, S. J.; Bae, I.; Shin, Y. J.; Park, Y. J.; Huh, J.; Park, S. M.; Kim, H. C.; Park, C. Nano Lett. 2010, 11, 138. doi: 10.1021/n1103094e

(12) Park, Y. J.; Kang, S. J.; Park, C.; Lotz, B.; Thierry, A.; Kim, K. J.; Huh, J. Macromolecules 2008, 41, 109. doi: $10.1021 / \mathrm{ma} 0718705$

(13) Kim, K. L.; Lee, W.; Hwang, S. K.; Joo, S. H.; Cho, S. M.; Song, G.; Cho, S. H.; Jeong, B.; Hwang, I.; Ahn, J. H.; Yu, Y. J. Nano Lett. 2015, 16, 334. doi: 10.1021/acs.nanolett.5b03882

(14) Bhavanasi, V.; Kusuma, D. Y.; Lee, P. S. Adv. Energy Mater. 2014, 4, 1400723. doi: 10.1002/aenm.201400723

(15) Sun, X.; Ma, C.; Wang, Y.; Li, H. J. Cryst. Growth 2002, 234, 404. doi: 10.1016/S0022-0248(01)01695-5
(16) Burbure, N. V.; Salvador, P. A.; Rohrer, G. S. Chem. Mater. 2010, 22, 5823. doi:10.1021/cm1018025

(17) Rosa, L. G.; Xiao, J.; Losovyj, Y. B.; Gao, Y.; Yakovkin, I. N.; Zeng, X. C.; Dowben, P. A. J. Am. Chem. Soc. 2005, 127, 17261. doi: $10.1021 / \mathrm{ja} 054159 \mathrm{t}$

(18) Fong, D. D.; Kolpak, A. M.; Eastman, J. A.; Streiffer, S. K.; Fuoss, P. H.; Stephenson, G. B.; Thompson, C.; Kim, D. M.; Choi, K. J.; Eom, C. B.; Grinberg, I. Phys. Rev. Lett. 2006, 96, 127601. doi: 10.1103/PhysRevLett.96.127601

(19) Chao, C.; Ren, Z.; Zhu, Y.; Xiao, Z.; Liu, Z.; Xu, G.; Mai, J.; Li, X.; Shen, G.; Han, G. Angew. Chem. Int. Ed. 2012, 51, 9283. doi: 10.1002/anie.201204792

(20) Jia, C. L.; Nagarajan, V.; He, J. Q.; Houben, L.; Zhao, T.; Ramesh, R.; Urban, K.; Waser, R. Nat. Mater. 2007, 6, 64. doi: $10.1038 /$ nmat 1808

(21) Fridkin, V. M. Ferroelectric Semiconductors, Consultants Bureau: New York, NY, USA 1980.

(22) Wang, F.; Lack, A.; Xie, Z.; Frübing, P.; Taubert, A.; Gerhard, R. Appl. Phys. Lett. 2012, 100, 062903. doi: 10.1063/1.3683526

(23) Salimi, A.; Yousefi, A. A. J. Polym. Sci. B: Polym. Phys. 2004, 42, 3487. doi: 10.1002/polb.20223

(24) Han, X.; Kuang, Q.; Jin, M.; Xie Z.; Zheng, L. J. Am. Chem. Soc. 2009, 131, 3152. doi: 10.1021/ja8092373

(25) Park, Y. J.; Kang, S. J.; Lotz, B.; Brinkmann, M.; Thierry, A.; Kim, K. J.; Park, C. Macromolecules 2008, 41, 8648. doi: 10.1021/ma801495k

(26) Guo, D.; Setter, N. Macromolecules 2013, 46, 1883. doi: 10.1021/ma302377q

(27) Urayama, K.; Tsuji, M.; Neher, D. Macromolecules 2000, 33, 8269. doi: $10.1021 / \mathrm{ma} 000855 \mathrm{w}$

(28) Prabu, A. A.; Lee, J. S.; Kim, K. J.; Lee, H. S. Vibrational Spectroscopy 2006, 41, 1-13. doi: 10.1016/j.vibspec.2005.11.005

(29) Li, W.; Guo, S.; Tang, Y.; Zhao, X. J. Appl. Polym. Sci. 2004, 91, 2903. doi: 10.1002/app.13503

(30) Shin, Y. J.; Kang, S. J.; Jung, H. J.; Park, Y. J.; Bae, I.; Choi, D. H. Park, C. ACS Appl. Mater. Interfaces 2011, 3, 582. doi: $10.1021 / \mathrm{am} 1011657$

(31) Zhu, H.; Mitsuishi, M.; Miyashita, T. Macromolecules 2012, 45, 9076. doi: 10.1021/ma301711g

(32) Guo, D.; Stolichnov, I.; Setter, N. J. Phys. Chem. B 2011, 115, 13455. doi: $10.1021 / \mathrm{jp} 2061442$ 
Supporting Information for Acta Phys. -Chim. Sin. 2017, 33 (6), 1261-1266

doi: $10.3866 /$ PKU.WHXB201702281

\section{钙钛矿铁电纳米片诱导的 P(VDF-TrFE) 取向生长}

刘金 ${ }^{1, \dagger}$ 麦江泉 ${ }^{2, \dagger}$ 李 诗 ${ }^{1}$ 任召辉 ${ }^{1, *}$ 李 铭 $^{1}$

武梦娇 $^{1}$ 吴勇军 $^{1}$ 路新慧 $^{2, *}$ 李 翔 $^{1}$ 田 鹤 $^{3}$

王宗荣 ${ }^{1}$ 韩高荣 ${ }^{1, *}$

( ${ }^{1}$ 浙江大学材料科学与工程学院, 硅材料国家重点实验室, 唐仲英传感材料及应用研究中心, 杭州 310027 ;

2 香港中文大学物理系, 香港 新界 999077; ${ }^{3}$ 浙江大学电子显微镜中心, 硅材料国家重点实验室,

材料科学与工程学院, 杭州 310027)

\section{Perovskite Ferroelectric Nanoplates Induced a Highly Oriented Growth of P(VDF-TrFE) Films}

\begin{tabular}{|c|c|c|c|c|}
\hline LIU Jin ${ }^{1, \dagger}$ & MAI Jiang-Quan ${ }^{2, \dagger}$ & LI Shi ${ }^{1}$ & REN Zhao-Hui ${ }^{1, *}$ & LI Ming ${ }^{1}$ \\
\hline WU Meng-Jiao" ${ }^{1}$ & WU Yong-Jun ${ }^{1}$ & LU Xin-Hui' ${ }^{2, *}$ & LI Xiang ${ }^{1}$ & TIAN $\mathrm{He}^{3}$ \\
\hline
\end{tabular}

( ${ }^{1}$ State Key Laboratory of Silicon Materials, School of Materials Science and Engineering, Cyrus Tang Center for Sensor Materials and Application, Zhejiang University, Hangzhou 310027, P. R. China; ${ }^{2}$ Department of Physics, Chinese University of Hong Kong, New Territories, Hong Kong 999077, P. R. China; ${ }^{3}$ State Key Laboratory of Silicon Material, School of Material Science \& Engineering, Center of Electron Microscope, Zhejiang University, Hangzhou 310027, P. R. China)

${ }^{*}$ Corresponding authors. REN Zhao-Hui, Email: renzh@ @ju.edu.cn.

LU Xin-Hui, Email: xhlu@ phy.cuhk.edu.hk. HAN Gao-Rong, Email: hgr@zju.edu.cn. 

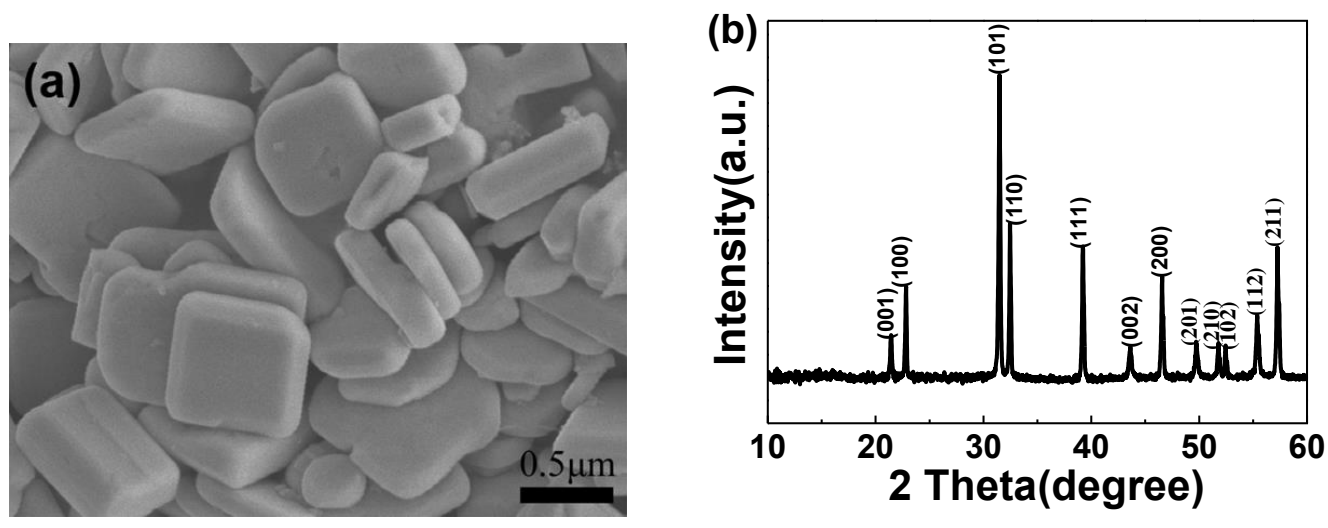

Fig.S1 (a) SEM image and corresponding (b) XRD pattern of PTO nanoplates.

As shown in Fig.S1a, $\mathrm{PbTiO}_{3}$ (PTO) nanoplates have a length of $\sim 600-800 \mathrm{~nm}$ and thickness of $\sim 150 \mathrm{~nm}$, adopting a tetragonal perovskite structure (Fig.S1b), where no any other impurity phases have been detected.

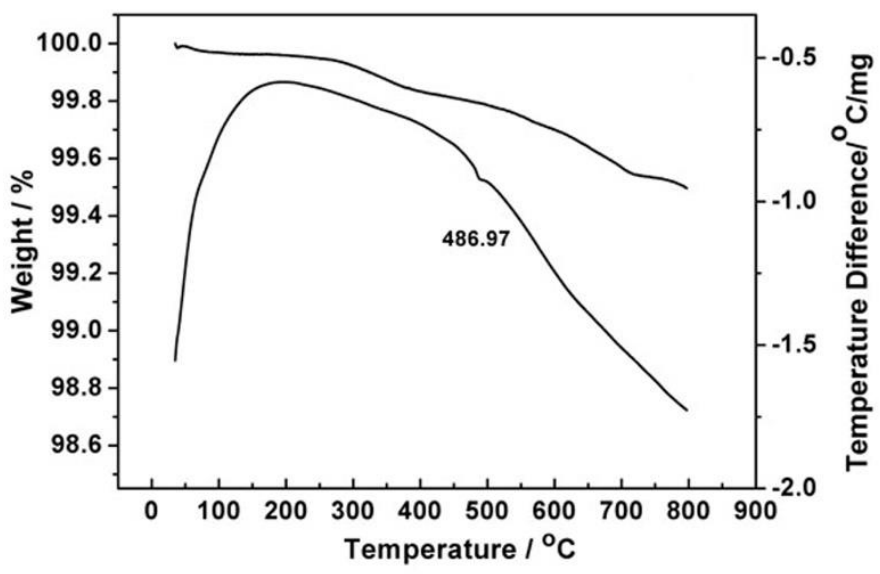

Fig.S2 TG-DTA curves of PTO nanoplates.

The little weight loss on the TG curve is due to volatile matter. One endothermic peak can be found on the DTA curve at temperature of about $487{ }^{\circ} \mathrm{C}$, very close to $490{ }^{\circ} \mathrm{C}$ of bulk PTO, implying a large $\mathrm{P}_{\mathrm{s}}$ of the nanoplates with an order of $60 \sim 70 \mu \mathrm{C} / \mathrm{cm}^{21}$. 

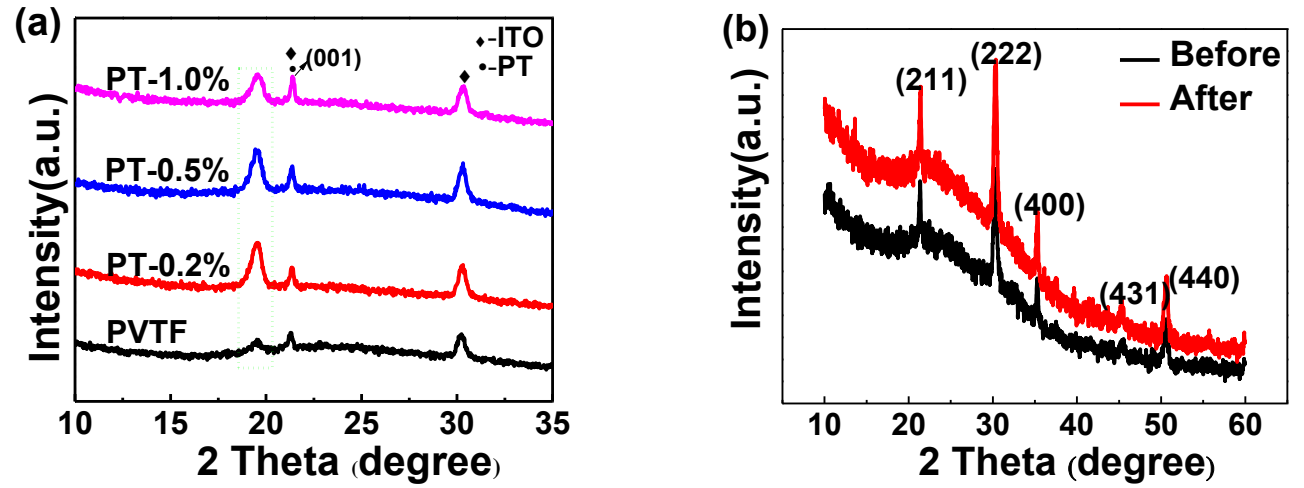

Fig.S3 (a) XRD patterns of ITO substrate and PVTF films with different concentration of PTO nanoplates and (b) ITO substrates before and after heat treatment at $180{ }^{\circ} \mathrm{C}$ for 2 hours.

XRD patterns of PVTF films with different concentration of PTO nanoplates were shown in Fig.S3a. A typical peak located at $\sim 19.8^{\circ}$ (highlighted by a green dotted rectangle) can be indexed as (110)/(200) of ferroelectric $\beta$ phase of PVTF. Among them, the intensity of this peak for PVTF $(0.2 \%)$ film is the highest, implying an orientation growth or improved crystallization of ferroelectric $\beta$ phase. The diffraction peak at $\sim 21.3^{\circ}$ was indexed into (001) of the tetragonal perovskite PTO, whereas no other related diffraction peaks from the tetragonal perovskite PTO (JCPDS 70-0746) have been observed. This suggests that the PTO nanoplates are lying down within the films, where (001) of PTO nanoplates was mainly exposed. One may argue that this diffraction could be originated from ITO substrate. In order to exclude this, XRD pattern of ITO substrates before and after heat treatment were collected, and the intensity of (211) peak at $21.3^{\circ}$ almost kept no change.

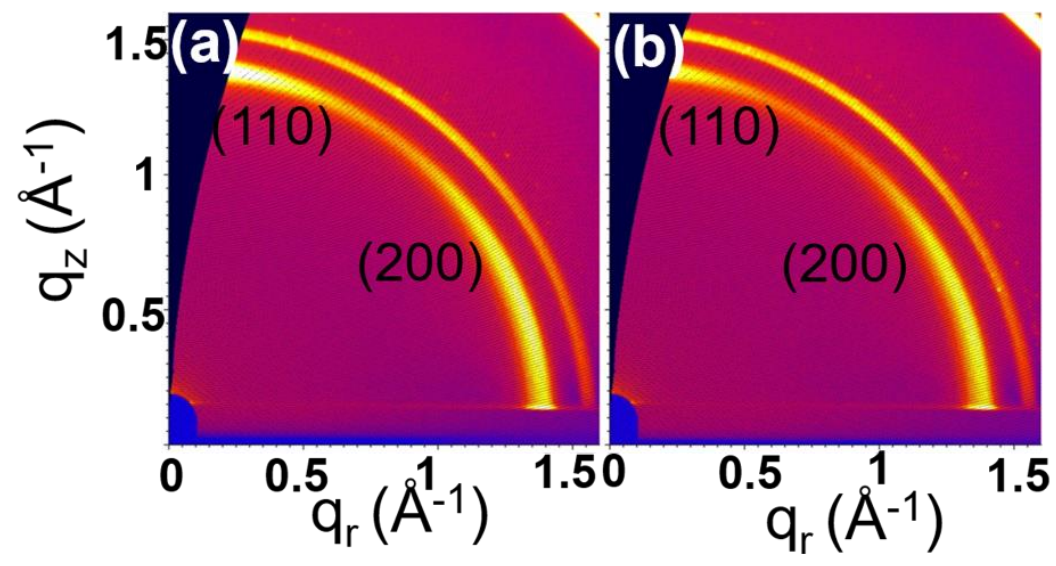

Fig.S4 GIWAXS patterns of PVTF films heated at $180{ }^{\circ} \mathrm{C}$ with (a) $0.5 \%$ and (b) $1.0 \%$ PTO nanoplates.

Fig.S4 shows GIWAXS patterns of PVTF films with $0.5 \%$ and $1.0 \%$ PTO nanoplates, respectively. PVTF $(0.2 \%)$ film shows the two distinct reflections on the meridian and $30^{\circ}$ away 
from the equator at $\mathrm{q}=1.4 \AA^{-1}$ which are indexed as (110) and (200). The similar phenomenon is also observed in the PVTF films with other concentration of PTO. Even though the intensity of these patterns are relatively weaker than that of PVTF $(0.2 \%)$ film, it can also be concluded that there is an orientation existing in PVTF films with $0.5 \%$ and $1.0 \%$ PTO nanoplates.

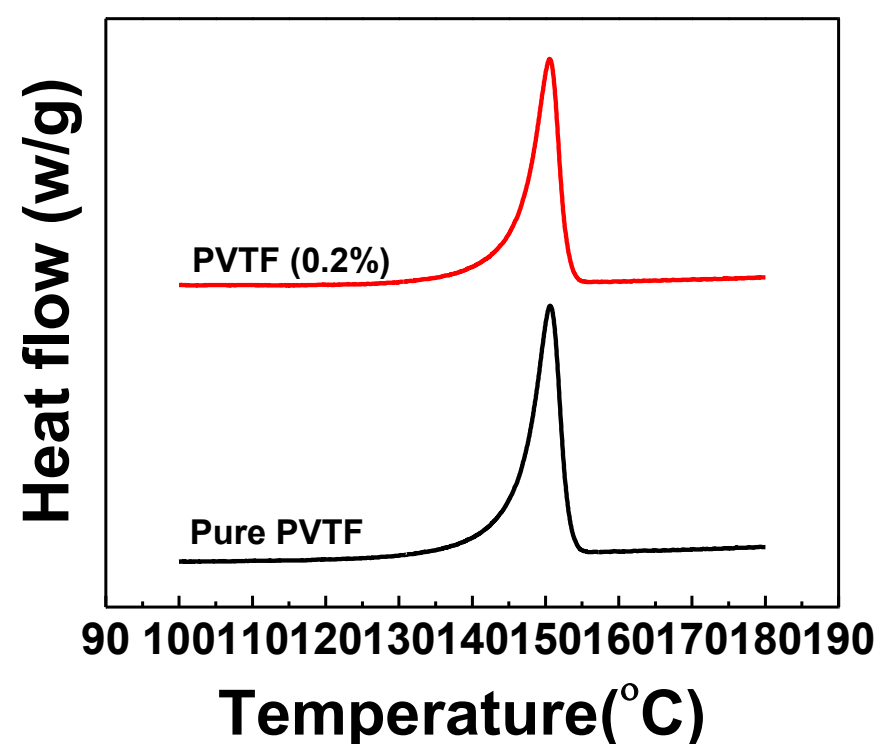

Fig.S5 DSC curves of pure PVTF film and PVTF (0.2\%) film.

In order to estimate the degree of crystallinity quantitatively, DSC technique was used and the calculation follows equation:

$$
X_{c}=\frac{\Delta H_{m}}{(1-W) \Delta H_{0}}
$$

where $\Delta \mathrm{H}_{\mathrm{m}}$ and $\Delta \mathrm{H}_{0}(45 \mathrm{~J} / \mathrm{g})$ are the melting enthalpy of the sample and the melting enthalpy for $100 \%$ crystalline sample, respectively ${ }^{2}$. And $W$ is the content of PTO nanoplates designed for the PVTF films. The $\Delta \mathrm{H}_{\mathrm{m}}$ values for pure PVTF films and PVTF (0.2\%) films are $26.81 \mathrm{~J} / \mathrm{g}$ and 27.61 $\mathrm{J} / \mathrm{g}$. The calculated $\mathrm{X}_{\mathrm{c}}$ by using equation (1) are $59.6 \%$ and $61.5 \%$ for pure PVTF films and PVTF $(0.2 \%)$ films. The results indicate the degree of crystallinity in pure PVTF film and PVTF $(0.2 \%)$ films is very close. 


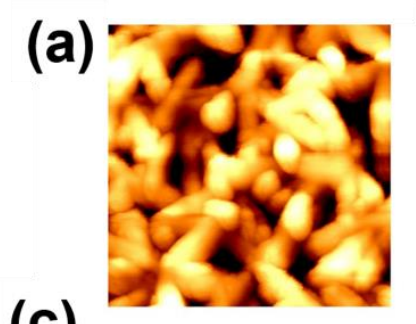

(c)

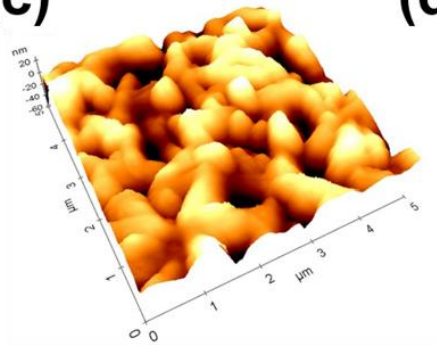

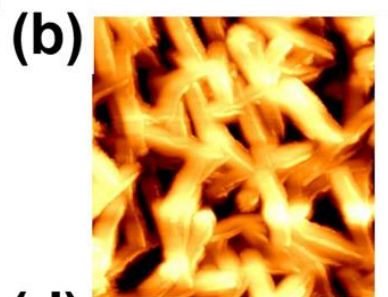

(d)

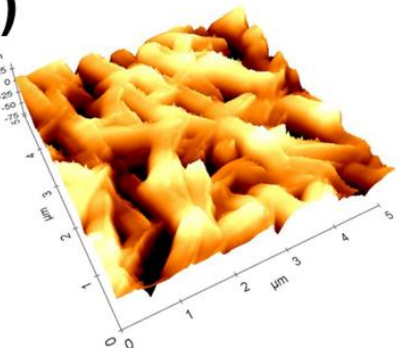

Fig.S6 AFM topographic images in height contrast of (a) pure PVTF and (b) PVTF (0.2\%) films and (c, d) corresponding 3D view images.

The topographic morphology determined by AFM imaging is obviously different from pure PVTF film to PVTF $(0.2 \%)$ film, and the corresponding shape changes from a particle to long-rod, as shown in Fig.S6a and 6b. On the basis of the corresponding 3D view image in Fig.S6c and 6d, an average diameter of the particles in pure PVTF (Fig.S6c) is statically about $0.38 \mu \mathrm{m}$, and the rods in PVTF (0.2\%) film in Fig.S6d have an average diameter of $\sim 0.45 \mu \mathrm{m}$ and length of $\sim 1.54 \mu \mathrm{m}$. These results lead us to argue that the significant change in the morphology of the samples should be attributed to the oriented growth of the films.

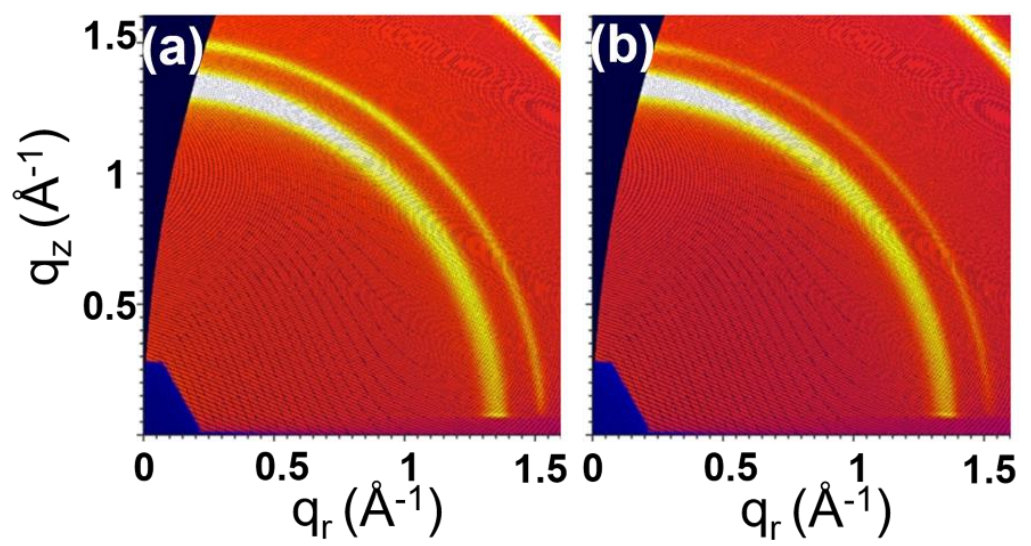

Fig.S7 GIWAXS patterns of (a) pure PVTF and (b) PVTF (0.2\%) films heated at $120{ }^{\circ} \mathrm{C}$ for 3 hours.

Fig.S7a and $7 \mathrm{~b}$ present GIWAXS patterns of pure PVTF and PVTF $(0.2 \%)$ films heating-treated at $120^{\circ} \mathrm{C}$ for 3 hours, and this temperature is below $\mathrm{T}_{\mathrm{m}}\left(\sim 150{ }^{\circ} \mathrm{C}\right.$ in Fig.S5). No intensified two reflections can be found in both patterns, confirming that a temperature above $T_{m}$ during the heating treatment is necessary for the oriented growth. 


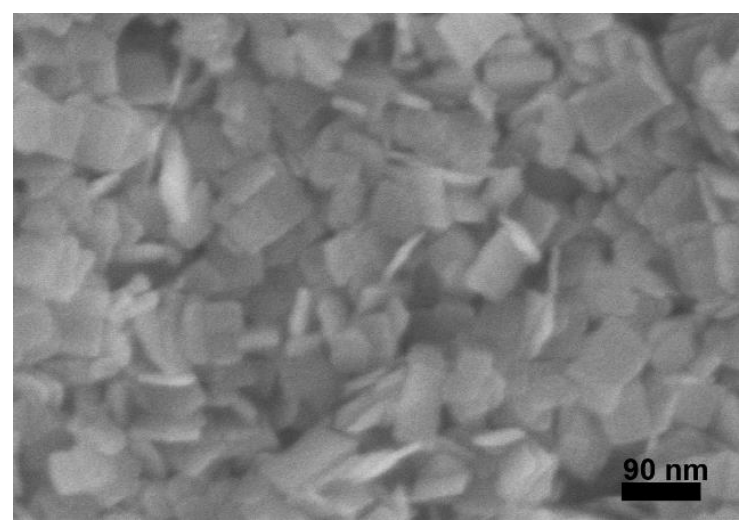

Fig.S8 SEM image of $\mathrm{TiO}_{2}$ nanoplates.

Fig.S8 shows SEM image of $\mathrm{TiO}_{2}$ nanoplates, synthesized by a hydrothermal synthesis method. The average length of $\mathrm{TiO}_{2}$ nanoplates was determined to be about $90 \mathrm{~nm}$ with a thickness of $\sim 6-10 \mathrm{~nm}$.
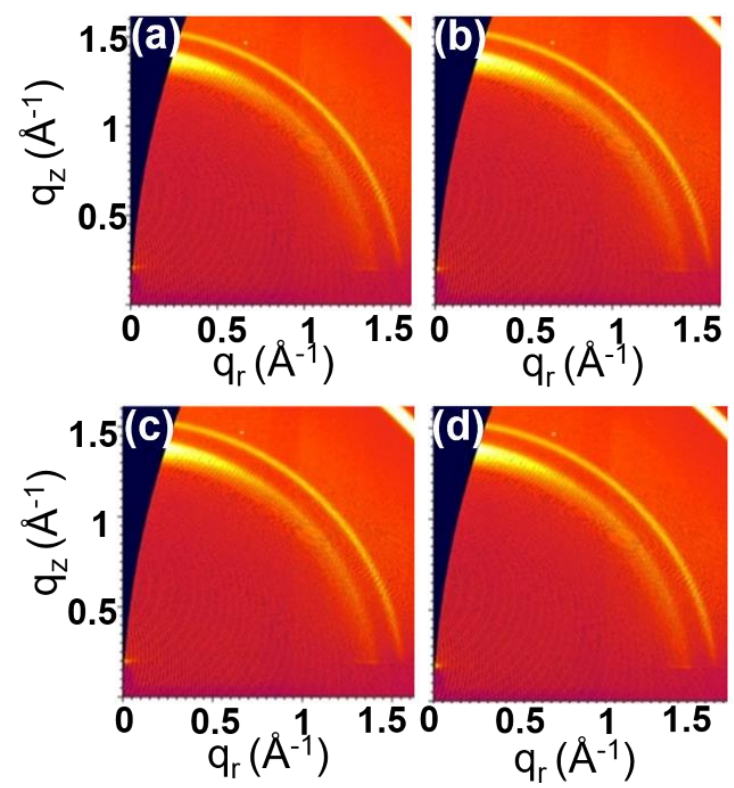

Fig.S9 GIWAXS pattern of PVTF films heated at $180{ }^{\circ} \mathrm{C}$ with different weight concentration of $\mathrm{TiO}_{2}$ (a) 0 , (b) $0.2 \%$, (c) $0.5 \%$ and (d) $1.0 \%$.

$\mathrm{TiO}_{2}$ is non-ferroelectric materials and its nanoplates were introduced into PVTF films for investigating the influence on the growth of the films. The corresponding GIWAXS patterns show that the intensified patterns only occur on the meridian, independent on an increasing of $\mathrm{TiO}_{2}$ concentration in Fig.S9 (a-d). It is thus reasonably to argue that the oriented growth of PVTF films originated from the ferroelectric polarization of PTO nanoplates. 


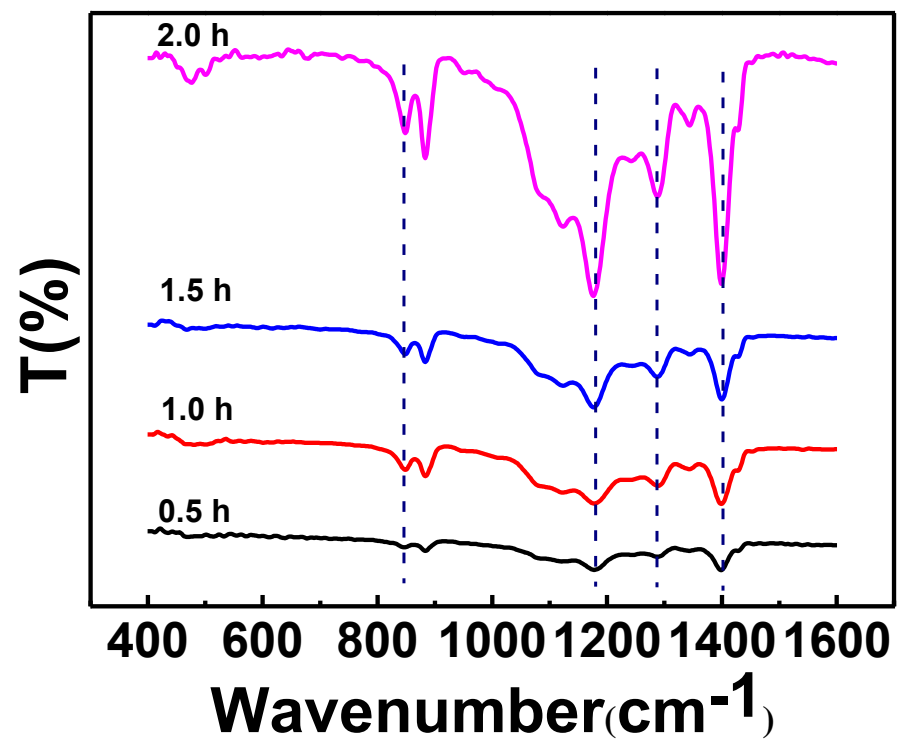

Fig.S10 FTIR spectra for PVTF (0.2\%) films heating treated for different time from $0.5 \mathrm{~h}$ to $2 \mathrm{~h}$ at $180{ }^{\circ} \mathrm{C}$.

Fig.S10 presents the FTIR spectra of PVTF (0.2\%) films heated for different time. The bands at $846 \mathrm{~cm}^{-1}, 1174 \mathrm{~cm}^{-1}, 1286 \mathrm{~cm}^{-1}$ and $1400 \mathrm{~cm}^{-1}$ can be indexed into the $\beta$ phase of PVTF. As the heating time prolonged, there is an obvious enhancement in the intensity of the band at $1400 \mathrm{~cm}^{-1}$, which is corresponding to the $\omega \mathrm{CH}_{2}$ coupled with $v_{\text {as }} \mathrm{C}-\mathrm{C}$ and thus highly sensitive to the chain orientation. Therefore, a large enhancement in the intensity of band at $1400 \mathrm{~cm}^{-1}$ could be attributed to the oriented growth of PVTF.
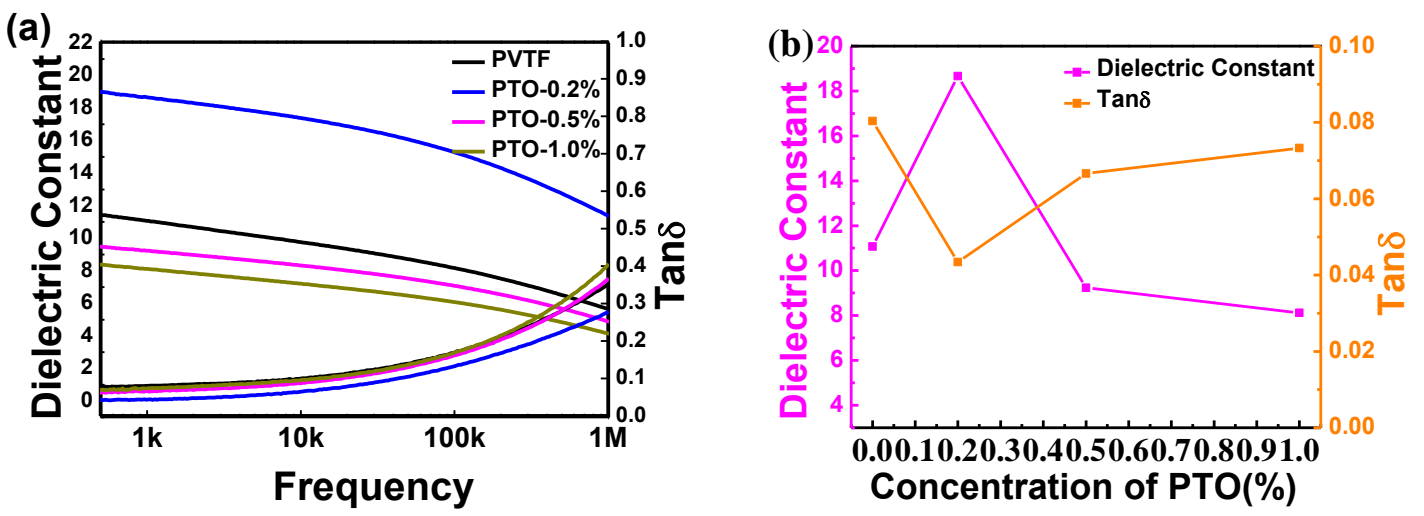

Fig.S11 Dielectric constant and dielectric loss curves of PVTF films with different concentration of PTO nanoplates from 0 to $1.0 \%$ under frequency (a) varied from $500 \mathrm{~Hz}$ to $1 \mathrm{MHz}$ and (b) $1 \mathrm{KHz}$ obtained from (a).

The dielectric constants and loss of PVTF films changed randomly, independent on the concentration of PTO nanoplates. In particular, PVTF (0.2\%) film demonstrates the best dielectric properties in Fig.S11a. It can be further derived from Fig.S11b that the corresponding loss of the 
PVTF $(0.2 \%)$ film is the lowest ( 0.043). This suggests that PVTF $(0.2 \%)$ film demonstrates the best dielectric property with the dielectric constant of $\sim 18.6$ and dielectric loss of $\sim 0.043$ at $1 \mathrm{KHz}$. However, more investigations are needed to explain why $0.2 \mathrm{w} \%$ is the optimized concentration of PTO nanoplates.

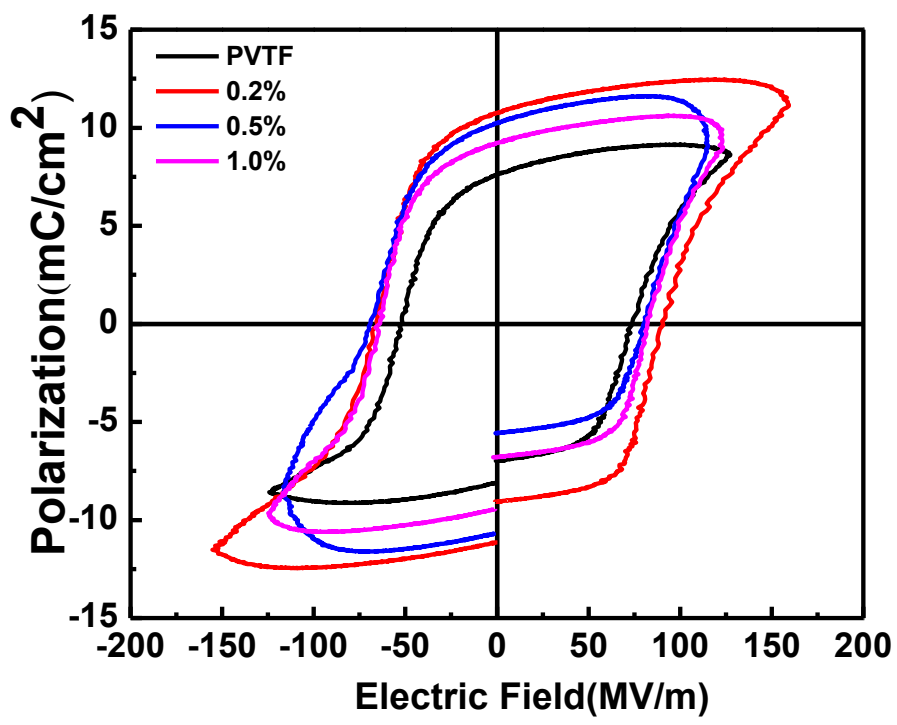

Fig.S12 Ferroelectric hysteresis loops of PVTF films with different concentration of PTO nanoplates.

Fig.S12 shows the ferroelectric hysteresis loops of PVTF films with different concentration of PTO nanoplates. The increased quantity of nanoplates is not beneficial for the interfaces between PTO and PVTF, leading to a large leakage current. This could be due to the increased interface between PTO nanoplates and PVTF films.

\section{References}

(1) Fridkin, V. M. Ferroelectric Semiconductors, Consultants Bureau: New York, NY, USA 1980

(2) Kuang, X.; Gao, Q.; Zhu, H. Appl. Polym. Sci. 2013, 129, 296. doi: 10.1002/APP.38729 